\title{
Novel treatment options for nonmelanoma skin cancer: focus on electronic brachytherapy
}

This article was published in the following Dove Press journal:

Medical Devices: Evidence and Research

26 November 2015

Number of times this article has been viewed

Michael E Kasper ${ }^{1,2}$

Ahmed A Chaudhary ${ }^{3}$

'Department of Radiation Oncology, Lynn Cancer Institute at Boca Raton Regional Hospital, Boca Raton, ${ }^{2}$ Charles E. Schmidt College of Medicine, Florida Atlantic University, FL, ${ }^{3}$ North Main Radiation Oncology, Warren Alpert School of Medicine, Brown University, RI, USA
Correspondence: Michael E Kasper Department of Radiation Oncology, Lynn Cancer Institute at Boca Raton Regional Hospital, 70I NW I3th Street, Boca Raton, FL, USA

Email mkasper@brrh.com

\begin{abstract}
Nonmelanoma skin cancer (NMSC) is an increasing health care issue in the United States, significantly affecting quality of life and impacting health care costs. Radiotherapy has a long history in the treatment of NMSC. Shortly after the discovery of X-rays and ${ }^{226}$ Radium, physicians cured patients with NMSC using these new treatments. Both X-ray therapy and brachytherapy have evolved over the years, ultimately delivering higher cure rates and lower toxicity. Electronic brachytherapy for NMSC is based on the technical and clinical data obtained from radionuclide skin surface brachytherapy and the small skin surface applicators developed over the past 25 years. The purpose of this review is to introduce electronic brachytherapy in the context of the history, data, and utilization of traditional radiotherapy and brachytherapy.

Keywords: electronic brachytherapy, superficial radiotherapy, skin surface brachytherapy, electron beam therapy, nonmelanoma skin cancer, basal cell carcinoma, squamous cell carcinoma
\end{abstract}

\section{Introduction}

Over three million nonmelanoma skin cancers (NMSCs) are treated each year in the United States, and the incidence continues to rise. Basal cell carcinoma (BCC) and squamous cell carcinoma (SCC) account for the overwhelming majority of NMSC.,2 Staging of NMSC is done using the American Joint Committee on Cancer Seventh Edition criteria, ${ }^{3}$ but formal staging and metastatic evaluation are infrequently performed since most lesions are stage T1 or T2. Although the mortality rate is low, NMSC significantly affects the patient's quality of life and is responsible for growing financial costs, and the number of procedures performed for NMSC in the United States doubled between 1994 and 2006. ${ }^{4}$ With the development of standardized brachytherapy techniques over the past 20 years and several new electronic brachytherapy (eBT) devices for the treatment of NMSC, the utilization of radiotherapy has surged. The purpose of this review is to introduce eBT in the context of the history, data, and utilization of traditional radiotherapy and brachytherapy.

Surgical options are most often utilized in the treatment of NMSC, but primary and adjuvant radiotherapy can make a major difference in outcomes. In many cases, radiotherapy can increase cure rates, and in others improve functional and cosmetic results. Generally recognized indications for the consideration of adjuvant radiotherapy include fixation to underlying structures, perineural involvement, poorly differentiated subtypes, recurrent disease, positive margins, and infiltrative growth patterns. Lesions with these unfavorable characteristics have higher recurrence rates with surgical management alone. Favorable lesions may benefit from primary radiotherapy, when it is unclear 
how extensive or complex a resection and/or reconstruction is required, as often occurs in lesions of the nose, ears, and lips, and near the eyes. In many of these cases, the functional and cosmetic result with radiotherapy will be superior with little or no compromise in the likelihood of cure. ${ }^{5}$

\section{X-ray therapy}

Low-energy radiation devices have been utilized for skin cancer treatment since the early days of radiotherapy. Within months of the discovery of X-rays in 1895, vacuum tubes producing X-rays were used to treat many skin conditions, including malignancies. By the turn of the 20th century, $\mathrm{X}$-rays were also used to treat other cancers, but it was quickly understood that only very superficial lesions could be effectively treated without causing severe toxicity. Grenz ray devices, producing what is now sometimes known as ultrasoft radiation, emerged in the late 1920s and were used in treating multiple cutaneous disorders. The Grenz ray devices produced "Grenz rays" in the 10-30 kV range and were widely incorporated into dermatological practices in the United States until the 1970s. As technology improved in the 1930s and 1940s, beam energy increased resulting in the development of superficial therapy devices, producing $\mathrm{X}$-rays in the $30-125 \mathrm{kV}$ range, and orthovoltage devices, producing 125-500 kV X-rays. Orthovoltage X-rays were considered "deep X-rays" and played an important role in radiotherapy until the development of the linear accelerator and the introduction of electron beam therapy. Older superficial and orthovoltage machines were decommissioned in the 1960s, 1970s, and 1980s in favor of electron beam therapy provided by linear accelerators. New superficial therapy devices have again become available and are playing an important role in the treatment of NMSC.

\section{Electron beam therapy}

Electron beam therapy became available with the development and rapid implementation of the linear accelerator in the late 1950s and 1960s. Typical courses of treatment ranged from 4 weeks to 7 weeks at standard fractionation and dosing. Electrons replaced the aging superficial and orthovoltage machines and were felt to provide more modern treatment, especially compared to cobalt teletherapy.

Low energy electrons and superficial photons continue to be widely used today for the treatment of NMSC. They are particularly useful for more invasive tumors or for insuring coverage of at-risk areas such as nodal basins. However, treating with electrons also poses several challenges. Low energy electrons have a significant "build up region" in tissues prior to reaching their maximum radiation dose, resulting in skin sparing. This build up region necessitates the addition of bolus, a material placed on the skin to build up the surface dose that can consist of sheets of a rubbery material, beeswax, or vaseline strips. Furthermore, electrons exhibit beam constriction on the surface and at depth, which leads to dose uncertainty, particularly in treating smaller fields as are often used for NMSC. Treating NMSC with electrons also requires treating more of the surrounding normal tissue. For instance, in a $3 \mathrm{~cm}$ treatment field, the $95 \%$ isodose area is $32 \%$ wider with $250 \mathrm{kV}$ orthovoltage than with $6 \mathrm{MeV}$ electrons, necessitating an increase in the treatment field by $1-1.5 \mathrm{~cm}$ in all directions for electron fields to achieve comparable coverage. ${ }^{6}$ Electrons also produce outward bowing low-dose isodose curves, resulting in a large penumbra. Moreover, secondary collimation consisting of lead cutouts or masks on the skin is often utilized, increasing physics and dosimetry workloads, and at least one study reports superior local control with orthovoltage compared to electrons. ${ }^{7}$

\section{Brachytherapy}

Brachytherapy is a targeted type of radiotherapy utilized in the treatment of many types of cancer. It is particularly relevant in this discussion as the justification and approvals of the skin eBT devices were based on clinical and safety data from modern high-dose rate (HDR) radionuclide skin surface applicators.

Brachytherapy is often described by the position of the isotope in relationship to the tumor, the isotope used, and the dose rate. Standard external beam radiotherapy, or teletherapy, is delivered by a linear accelerator and given at a distance from the patient, while brachytherapy is delivered with needles or catheters within the tumor (interstitial), an applicator within a cavity (intracavitary), or an applicator adjacent to the tumor as in skin surface brachytherapy. Most of the early brachytherapy was delivered with low-dose rate (LDR) or medium-dose rate (MDR) sources, including ${ }^{226}$ Radium and ${ }^{222}$ Radon, which are no longer used in the United States. ${ }^{131}$ Cesium, ${ }^{125}$ Iodine, and ${ }^{103}$ Palladium are frequently used today to deliver LDR brachytherapy for prostate cancer, gynecological cancers, and occasionally other interstitial treatments. Dose rate of 0.4-2 Gy per hour is classified as LDR. Dose rate of 2-12 Gy per hour is classified as MDR, and dose rate of $>12$ Gy per hour is classified as HDR.

Radioactive surface molds and interstitial brachytherapy, along with superficial and orthovoltage therapy, were the 
established radiation modalities for many years in treating NMSC. With the advent of the linear accelerator and increasing availability of electron beam therapy, surface and interstitial brachytherapy fell out of favor and resident trainees had little familiarity with this treatment option. Radiation protection concerns were an additional reason for moving away from brachytherapy. ${ }^{8}$

The development in the late 1960s of the HDR brachytherapy afterloader, a robotic controller for automated insertion and removal of the radioactive source through catheters placed in or near the tumor, greatly improved radiation protection and simplified the delivery of the source. The HDR brachytherapy afterloader was slowly accepted in the United States and there was some controversy regarding the radiobiology of LDR versus HDR. However, HDR now enjoys widespread acceptance, and there is an increasing body of literature postulating the advantages of hypofractionation and HDR. ${ }^{9,10}$ Most of the nonprostate brachytherapy today is delivered with HDR brachytherapy afterloaders using ${ }^{192}$ Iridium.

While there is little level I evidence for traditional radiotherapy in the management of NMSC, there is no level I evidence for HDR brachytherapy. However, several retrospective and prospective studies with excellent results and adequate follow-up have been reported. Guix et al described a standardized surface mold technique prospectively utilizing HDR brachytherapy. One hundred and thirty-six patients with NMSC achieved 5-year local control of 98\% with excellent treatment tolerance and no severe early or late complications. Fractionation was standard at 1.8 Gy per fraction, and total doses were in the range of 60-80 Gy. ${ }^{11}$ Additionally, Kohler-Brock et al reported 10-year followup on diseases of the skin and mucosal membranes using a standardized surface applicator, achieving 92\% local control. The total dose was 30-40 Gy in 5-10 fractions delivered once or twice per week. No severe late reactions were reported. ${ }^{12}$ More recently, Gauden et al reported data on 200 patients with 236 NMSC treated with a standardized HDR applicator. With a median follow-up of 66 months, the local control was $98 \%$, and cosmesis was good to excellent in $88 \%$ of patients. ${ }^{13}$ Finally, Tormo et al reported results of a prospective trial with a standardized applicator (the Valencia applicator). Thirty-three patients with 48 NMSC received 42 Gy in 6 fractions. Local control was $98 \%$ at a median follow-up of 47 months. All patients developed grade 1 toxicity with the exception of one who developed a grade 2 toxicity. ${ }^{14}$ These studies, and others, form the clinical and technical justification for eBT for NMSC.

\section{Electronic brachytherapy}

The currently available eBT devices are the $\mathrm{Xoft}^{\circledR} \mathrm{Axxent}^{\circledR}$, Zeiss $^{\circledR}$ INTRABEAM $^{\circledR}$, and Elekta ${ }^{\circledR}$ Esteya $^{\circledR}$. The Xoft Axxent electronic brachytherapy system ${ }^{\circledR}$ (iCAD Inc., Nashua, $\mathrm{NH}, \mathrm{USA}$ ) incorporates a $23 \mathrm{~mm}$ proprietary X-ray source with a multilumen catheter and is used in the treatment of skin cancer, early stage breast cancer, and gynecological malignancies (Figure 1). ${ }^{15,16}$ It consists of a mobile controller that provides power and cooling to the source, a HDR X-ray source, and applicator sets. Superficial, NMSCs are treated using United States Food and Drug Administration (FDA) approved, lightweight surface applicator placed directly over the target lesion. Surface applicators measure $10 \mathrm{~mm}, 20 \mathrm{~mm}$, $35 \mathrm{~mm}$, and $50 \mathrm{~mm}$ in diameter with corresponding end caps (Figure 2). ${ }^{15}$ Similar to radionuclide HDR brachytherapy, the miniature X-ray source can be stepped along the catheter

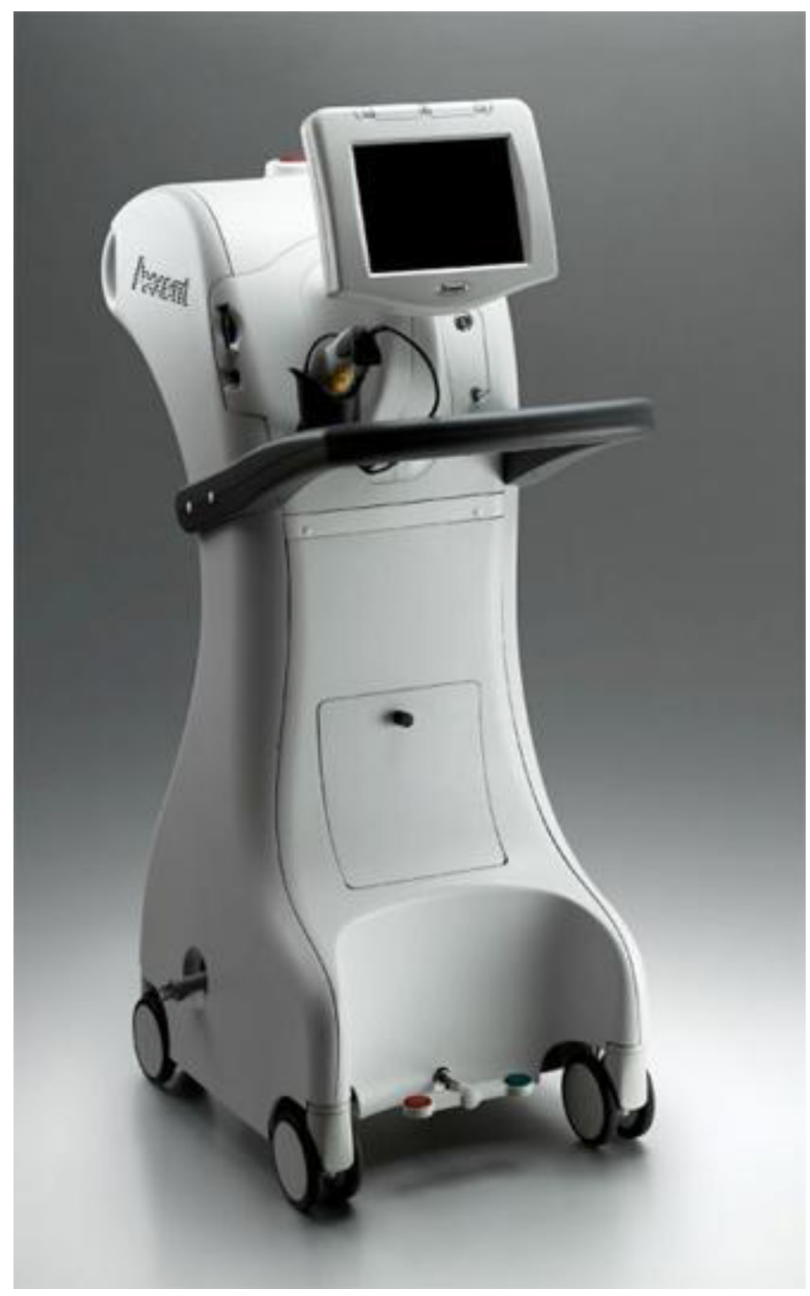

Figure I The Xoft $^{\circledast}$ Axxent ${ }^{\circledast}$ electronic brachytherapy system (iCAD, Inc.) external trolley.

Note: Reproduced from Xoftlnc.com [homepage on the Internet]. Axxess with Axxent: Innovative Technology for the Practice of Radiation Oncology. California: Xoft, inc.; 2008. Available from: http://www.xoftinc.com/treatingebx.html. ${ }^{15}$ 


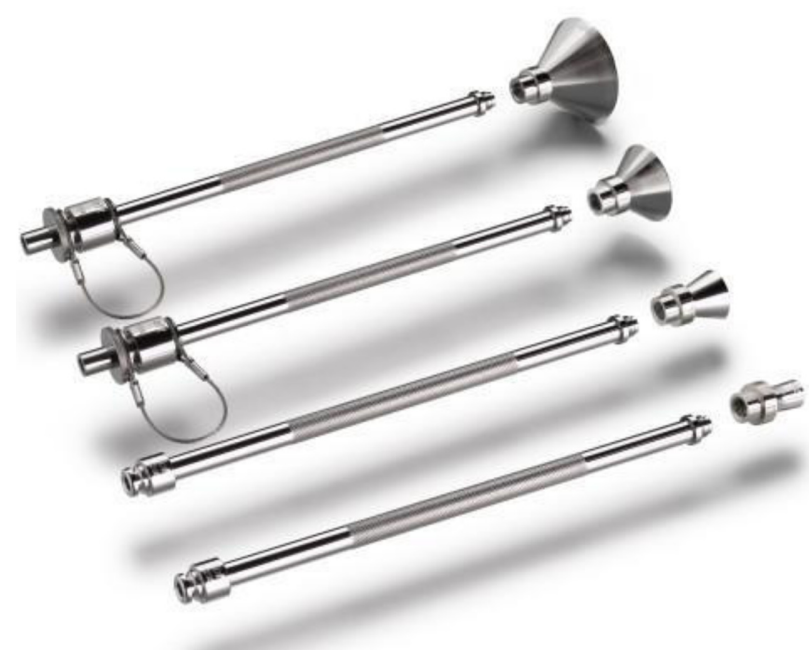

Figure 2 Surface applicators for the $\mathrm{Xoft}^{\circledR}$ Axxent ${ }^{\circledR}$ Electronic Brachytherapy System (iCAD, Inc.) of differing diameter size.

Note: Reproduced from Bhatnagar A, Loper A. The initial experience of electronic brachytherapy for the treatment of non-melanoma skin cancer. Radiat Oncol. 2010;5:87.40

to deliver the optimal treatment. Low-energy photons are generated in the source by accelerating electrons that then strike a tungsten target. The source to skin distance (SSD) is $25 \mathrm{~mm}$. The X-ray source tube diameter is $2.25 \mathrm{~mm}$, and the $\mathrm{X}$-ray source has a power of $50 \mathrm{~W}$. The controller has a beam current of $300 \mu \mathrm{A}$ and a selectable high-voltage output with maximum photon energy of $50 \mathrm{kV}$. Typical treatment time is 4-10 minutes, and the maximum number of treatments per $\mathrm{X}$-ray source is $250-500$ minutes of treatment. ${ }^{15-17}$

The Axxent eBT treatment produces a similar dose distribution to an HDR ${ }^{192}$ Ir source, but does not require a radiation vault or heavy shielding because it generates low-energy photons. ${ }^{15,18}{ }^{192}$ Ir produces a complicated X-ray spectrum, when it decays with an average energy of $0.38 \mathrm{mV}^{18}$ In contrast, the radiation generated from the Axxent can be turned on and off, and the average energy of its photons is only $26.7 \mathrm{kV}{ }^{16}$ The flattening filter allows a uniform dose distribution to be delivered to the surface and to depths below the skin. Dosimetric study of treatment with the system has shown that the radiation field is tightly conformal around the applicator and the dose penumbra, or fall-off region, is $\sim 2 \mathrm{~mm}$ and small enough to spare adjacent tissues. Surface doses range from $126 \%$ to $174 \%$ of the prescribed dose for prescriptions to $2-5 \mathrm{~mm}$ depth. Radiation is delivered at a nominal dose rate of $0.6 \mathrm{~Gy} / \mathrm{min}$ at $3 \mathrm{~cm}$ depth. ${ }^{15,16}$ The Xoft Axxent Electronic Brachytherapy System has been available commercially since 2009 .

The INTRABEAM PRS500 electronic Brachytherapy System (Carl Zeiss Surgical, Oberkochen, Germany) is a mobile $\mathrm{X}$-ray source that was initially developed to treat intracranial lesions and can be used to treat a variety of malignant lesions (Figure 3). ${ }^{19}$ Like the Xoft Axxent, it can be used to treat

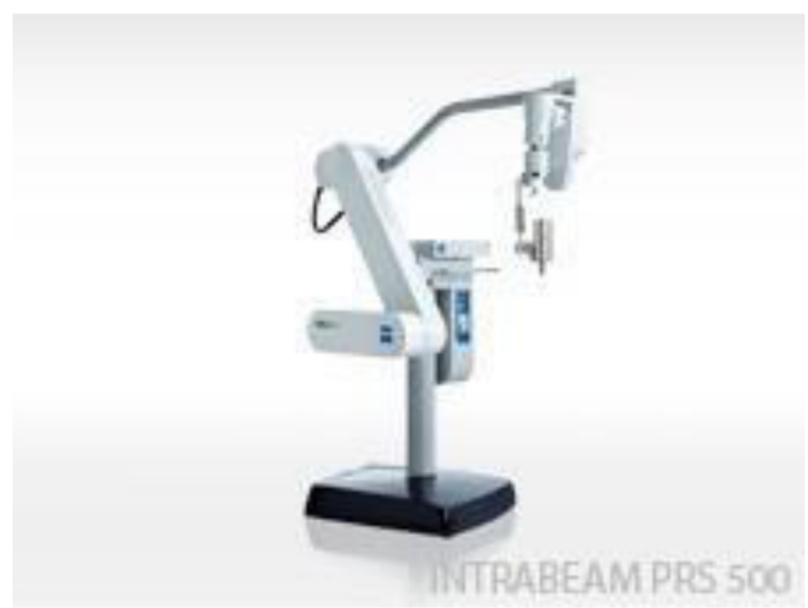

Figure 3 The Zeiss ${ }^{\circledR}$ INTRABEAM $^{\circledR}$ (Carl Zeiss Surgical) PRS500 Electronic Brachytherapy System.

Note: Reproduced from Zeiss.com [homepage on the Internet]. INTRABEAM: Precision and Ease of Use. Jena, Germany: Carl Zeiss Meditec AG, 20I4. Available from: http:// www.zeiss.com/meditec/en_us/products-solutions/intraoperative-radiotherapy/ intrabeam-for-breast-cancer/intrabeam.html. Accessed June II, 20I5. ${ }^{19}$

skin, breast, and gynecological cancers, but also has a needle applicator that can be applied to treat spinal metastases. ${ }^{15,19}$ The system consists of an X-ray source, a control console, a user terminal, and attachments to verify accurate treatment. Treatment times are entered into the control console, and one of the four flat applicators for surface treatment is attached to the probe and used to deliver the dose. Treatment times range between 5 minutes and 30 minutes. Applicators for surface treatment are available in $10 \mathrm{~mm}, 20 \mathrm{~mm}, 30 \mathrm{~mm}$, and $40 \mathrm{~mm}$ diameter and can be sterilized and reused (Figure 4). ${ }^{19}$ The miniature X-ray source, the XRS 4, measures $11 \mathrm{~cm}$ in length and has a $3.2 \mathrm{~mm}$ diameter probe. The SSD is variable between $9.6 \mathrm{~mm}$ and $21.6 \mathrm{~mm}$ based on the applicator size

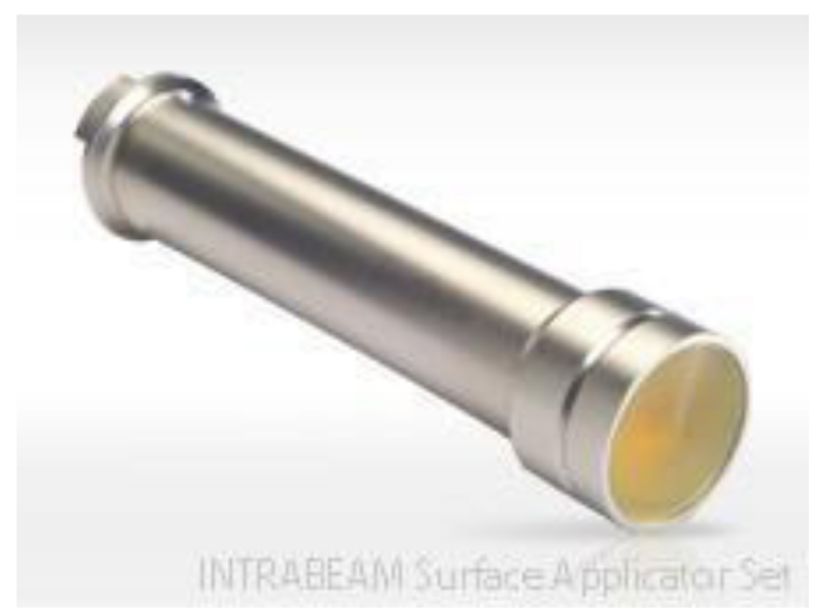

Figure 4 A surface applicator used for electronic brachytherapy with the Zeiss ${ }^{\circledR}$ INTRABEAM $^{\circledR}$ (Carl Zeiss Surgical) PRS500 System.

Note: Reproduced from Zeiss.com [homepage on the Internet]. INTRABEAM: Precision and Ease of Use. Jena, Germany: Carl Zeiss Meditec AG, 2014. Available from: http:/l www.zeiss.com/meditec/en_us/products-solutions/intraoperative-radiotherapy/ intrabeam-for-breast-cancer/intrabeam.html. Accessed June II, 20I5. ${ }^{19}$ 
and the filter. Like the Axxent, the INTRABEAM produces maximum photon energies of $50 \mathrm{kV}$ via the interaction of accelerated electrons with a gold target and requires minimal shielding. Beam current can be set between $5 \mu \mathrm{A}$ and $40 \mu \mathrm{A}$, and photons are emitted in an isotropic pattern from the end of the probe. The source also contains a beam deflector and an internal radiation monitor that continuously monitors the treatment to measure the dose delivered. The INTRABEAM has a dose rate of $\sim 2 \mathrm{~Gy} / \mathrm{min}$ at $1 \mathrm{~cm}$ of water. ${ }^{17,19,20}$ The INTRABEAM PRS500 skin Electronic Brachytherapy System has been commercially available since 2013 .

The Esteya Electronic Brachytherapy System (Elekta AB-Nucletron, Stockholm, Sweden) was developed specifically for the treatment of skin surface lesions (Figure 5). ${ }^{21}$ It consists of a treatment control panel with planning software, a treatment unit, and surface applicators. The applicator diameters for treatment are $10 \mathrm{~mm}, 15 \mathrm{~mm}, 20 \mathrm{~mm}, 25 \mathrm{~mm}$, and $30 \mathrm{~mm}$, and a $0 \mathrm{~mm}$ applicator is used for quality assurance

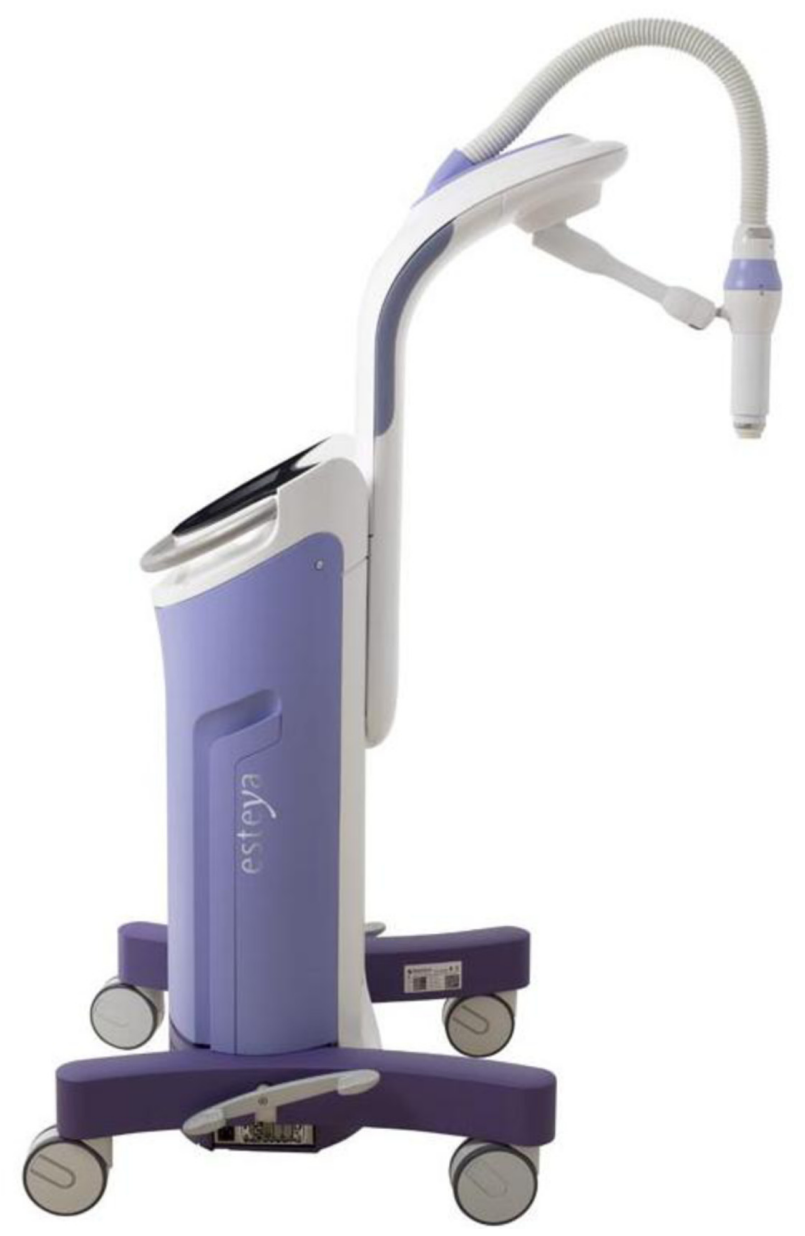

Figure 5 The Estey ${ }^{\circledR}$ Electronic Brachytherapy System (Elekta ${ }^{\circledR}$ AB-Nucletron, Stockholm, Sweden).

Note: Reproduced from Esteya.com [homepage on the Internet]. Esteya Electronic Brachytherapy for Treating Skin Cancer. Sweden: Elekta AB, 20I5. Available from: http://www.esteya.com. ${ }^{21}$

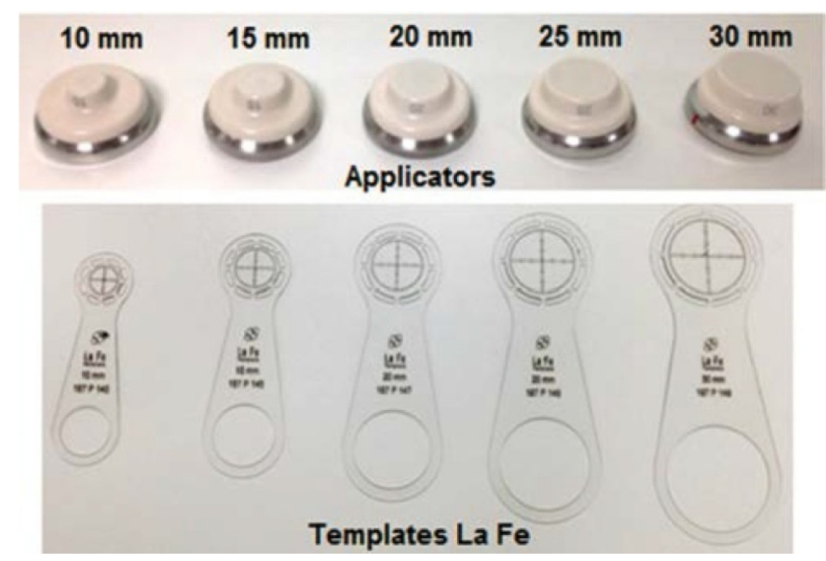

Figure $\mathbf{6}$ Esteya applicators of differing collimator diameters and the corresponding templates La Fe used to mark the outer diameter of each applicator.

Note: Reproduced from Pons-Llanas O, Ballester-Sánchez R, Celada-Álvarez FJ, et al. Clinical implementation of a new electronic brachytherapy system for skin brachytherapy. J of Contemp Brachytherapy. 2015;6(4):417-423.22

(Figure 6). ${ }^{17,21}$ The treatment unit can generate a light field to assist in set up, but a template centering the lesion and directing placement of the applicator, as designed by the Valencia group, greatly simplifies treatment and improves accuracy (Figure 6). ${ }^{22}$ The Esteya utilizes a collimated, miniature X-ray source that has a fixed voltage of $69.5 \mathrm{kV}$. It uses a variable beam current, which is nominally set at $1.6 \mathrm{~mA}$, but self adjusts to $1.0 \mathrm{~mA}$ for doses of $2-4 \mathrm{~Gy}$ and $0.5 \mathrm{~mA}$ for doses $<2 \mathrm{~Gy}$. Treatment times for surface lesions are generally $2-3$ minutes, and the surface dose is $120 \%$ of the specified dose, when the specified dose is normalized to $3 \mathrm{~mm}$ depth. The source requires maintenance every 4,000 fractions..$^{21,23}$

The Esteya was designed to deliver a similar radiation dose distribution to the Valencia HDR-applicator, and similarly, each of its applicators contains a flattening filter. ${ }^{16,24}$ The $1.6 \mathrm{~mm}$ aluminum flattening filter differentially absorbs emitted photons to flatten the radiation beam and produces a uniform dose both on the skin and at depth. This uniform dose allows for treatment of the entire depth of the tumor. ${ }^{21} \mathrm{At}$ $3 \mathrm{~mm}$ depth, it delivers radiation at a dose rate of $2.7 \mathrm{~Gy} / \mathrm{min}$, and measurements of dose symmetry have shown 95\%-105\% within $5 \mathrm{~mm}$ depth of the surface. ${ }^{21,23}$ Additionally, the penumbra is small, $\sim 1 \mathrm{~mm}$, which spares adjacent tissues. ${ }^{23}$ The Esteya has been available commercially since early 2014. Dosimetric characteristics of all three devices have been previously described. ${ }^{17,23}$ Table 1 provides a comparison of several of the physical characteristics of the three devices.

Two studies have been published reporting clinical results representing two of the three types of devices currently available. Bhatnagar initially reported 1-year outcomes with the Xoft Axxent system in 2013 and updated his results in abstract form at the American Society for Radiation Oncology annual 
meeting in 2014. One hundred and eighty-seven patients with 277 NMSC lesions were treated to a dose of 40 Gy in 8 fractions over 4 weeks. Mean follow-up was 13 months. One hundred sixty-eight lesions had follow-up of at least 1 year, and no recurrences were observed. Cosmesis was "excellent" in $96 \%$ of patients and "good" in 3\% at 1-year follow-up. No grade 3 toxicity was seen. ${ }^{25}$ Ballester-Sánchez et al recently reported the Hospital Le Fe experience with Esteya. Twenty patients with 23 lesions were treated to a dose of 42 Gy in 6 fractions over 3 weeks. All patients had 6 months follow-up. Lesion size was limited to $20 \mathrm{~mm}$ in diameter and $4 \mathrm{~mm}$ depth, which was confirmed histopathologically with punch biopsy and radiographically with high-frequency ultrasound. A complete response was documented for all lesions and no grade 3 toxicity was seen. The authors acknowledge that the short follow-up and small number of patients are limitations of the study. ${ }^{26}$

\section{Discussion}

Radiotherapy for NMSC is likely underutilized. Despite the fact that radiotherapy has been well utilized $>100$ years in the treatment of skin cancers, it is still considered as an afterthought by many clinicians. Modern day radiation oncologists are well trained in the treatment of skin cancer, and although the exposure to some modalities of treatment may be limited, the clinical results are excellent. Studies reporting results on primary radiotherapy for skin cancer treatment in which adequate doses are utilized consistently show excellent results. ${ }^{27,28}$ In studies reporting high-failure rates, association with larger tumors and low-biological equivalent dose is consistently shown. ${ }^{29}$ Culleton et al showed that when multimodality teams evaluated skin cancer patients, radiotherapy was recommended in $19 \%$ of cases compared to $1 \%$, when a multimodality team was not utilized..$^{30}$

Patients referred for radiotherapy are often selected due to tumor location, larger tumor size, more aggressive histopathology, or positive margins. Patient age and patient preference are also frequently cited reasons for referral. ${ }^{27,31}$ The comparison of outcomes for clinically staged patients - the majority of radiotherapy treatment patients - versus pathologically staged patients is inherently biased since there is more likely to be an underestimation of disease in clinically staged patients. Nevertheless, multiple welldesigned studies with long follow-up show recurrence rates $<5 \%$ for primary radiotherapy in treatment of $\mathrm{T} 1$ and $\mathrm{T} 2$ BCC and SCC lesions. ${ }^{27}$ Petrovich et al showed 5-, 10-, and 20 -year control rates of $99 \%, 98 \%$, and $98 \%$, respectively, for 502 tumors of $2 \mathrm{~cm}$ or smaller. ${ }^{28}$ Only one prospective, randomized study has directly compared surgery with radio- therapy. ${ }^{32}$ Avril et al reported on 347 patients randomized to either surgery or various types of radiotherapy for lesions of the face measuring up to $4 \mathrm{~cm}$. The recurrence rate at 4 years was reported as $0.7 \%$ in the surgery group and $7.5 \%$ in the radiotherapy group. It should be noted that $55 \%$ of the radiotherapy group were treated with interstitial brachytherapy, a technically challenging and nonstandardized technique, requiring a 5-7 days hospitalization at the time. Another $1 / 3$ of the radiotherapy group received contact therapy. Conventional radiotherapy was used in only the 20 largest lesions. Except one, all of the radiotherapy failures were in the interstitial brachytherapy or contact therapy group. ${ }^{32}$ Another prospective, randomized study showed radiotherapy superior to cryotherapy with a recurrence rate at 2 years of $39 \%$ for cryotherapy versus $4 \%$ for radiotherapy. ${ }^{33}$

Shortly after its discovery in $1898,{ }^{226}$ Radium was recognized to be suitable for internal treatments as well as on the skin surface. These internal treatments were the first brachytherapy experience. Brachytherapy techniques have evolved over the years, but they have frequently consisted of rarely used methods and applicators well known by only one or two individuals of a given radiotherapy department. The techniques varied significantly from patient to patient and department to department, and the learning curve in mastering these techniques was steep. Applicators were highly variable, and this was especially true for skin surface brachytherapy, where custom molds or elaborate applicators were constructed over many days in the physics lab to precisely conform to the needs of each individual patient. NMSC was frequently managed with interstitial brachytherapy, particularly for larger lesions, and dose inhomogeneity with poor cosmetic outcomes was common. The early data reflect this variability in techniques with variable cure rates and complications. Alam et al recently published a critical review of brachytherapy techniques for NMSC. ${ }^{34}$ The variability and inconsistency in techniques decreased significantly in the early 1990s with LDR prostate brachytherapy, where patient volumes were such that efficiency and standardization were achieved. Standard, easy to use, skin surface HDR applicators, and surface molds began emerging 15-20 years ago and have seen a rapid acceptance among the radiotherapy community. ${ }^{35}$ These surface applicators and standardized molds have simplified surface treatment to achieve excellent reproducibility and efficiency. These techniques have demonstrated good clinical effectiveness and little early or late morbidity. ${ }^{11-14}$

Brachytherapy provides several benefits over traditional radiotherapy. Since radiation is delivered very close to or within the tumor, little normal tissue is exposed to the radiation. Treat- 
ment fields utilizing smaller margins are possible resulting in a more precise treatment. Late toxicity and poor cosmetic results are associated with increased volume of irradiated skin. ${ }^{36}$ This improved targeting allows higher, more effective radiation doses to be delivered over shorter treatment times. For instance, a typical course of radiotherapy that takes 6-8 weeks of daily treatment can be completed with brachytherapy in as little as 1-2 weeks. ${ }^{37}$ As in superficial and orthovoltage therapies, there is no build up region with skin surface brachytherapy, so bolus is not necessary. Many of the advantages of brachytherapy can be duplicated with superficial therapy or orthovoltage therapy. Recently, superficial X-ray producing machines have become widely available again, and the new portable versions, one equipped with high-frequency ultrasound, may be strong competitors with brachytherapy for treating NMSC. Electron beams produce uneven air gaps between the tip of the electron cone and curved surfaces on patients producing dose inhomogeneity at depth. Brachytherapy surface molds can follow the contour of the skin and deliver the prescribed dose uniformly throughout the target volume due to computerized algorithms that allow dose optimization.

Dermatologists have had an inconsistent but long history with radiotherapy. Dermatologists or surgeons performed many of the initial cancer treatments with brachytherapy. Sixty years ago, many dermatologists received training in delivering Grenz rays for treatment of superficial skin cancers and other skin diseases and incorporated these treatments into their practices. This exposure to radiotherapy fell out of favor in the past 25 years and has become much less common. Most Grenz ray machines have since been decommissioned.

Many dermatologists have once again enthusiastically embraced radiation therapy devices that they can incorporate into their practices. This has gone as far as hiring radiation oncologists in those states with restrictions on use of certain equipment or isotopes. ${ }^{38}$ In one particularly critical article, eBT is described as an untested and unproven modality, with little or no recognition that dosimetrically and clinically, the radiation effects mimic isotopic HDR brachytherapy. In the same forums in which eBT, or radiotherapy in general, is criticized, other commenters praise the new, mobile superficial radiation therapy (SRT) devices that due to their lower treatment energy and dose rate can be used by dermatologists without a radiation oncologist. Whereas, most dermatologists argue that radiotherapy is inferior to surgery, here it is claimed that SRT provides the same outcomes as Mohs surgery - " $95 \%+" .{ }^{38}$

The American Academy of Dermatology has issued a statement on SRT and eBT for cutaneous BCC and SCC, approved by the Academy's Board of Directors in November of 2013. In addition to supporting surgical treatment as the optimal primary intervention for BCC's and SCC's, they support consideration of SRT as a second-line option for use in special circumstances. They stated, however, that it is their belief that additional research is needed for both SRT and eBT. They also warned that care should be taken to use proper current procedural terminology (CPT) coding and that a dermatologist should not administer eBT. ${ }^{39}$

While several dosimetric and technical papers have been published regarding the three available eBT devices, ${ }^{22,40}$ very little clinical data have been published. The two studies referenced above represent the two most mature reports for the respective devices. Few patients are $>2$ years from the onset of treatment. Since NMSC may recur long after treatment, 5 years or greater follow-up is required for data to be meaningful. Eighteen percent of treatment failures occur between 5 years and 10 years after treatment, regardless of whether that treatment is surgery or radiotherapy. ${ }^{41}$ Nevertheless, the preliminary reports of eBT do show excellent responses, and there is the expectation that the results will mirror the excellent results of radionuclide skin surface brachytherapy. In addition, there are clear advantages of eBT over radionuclide skin surface brachytherapy. These small mobile devices do not require a dedicated treatment vault and avoid the radiation safety issues and expense of storing and regularly replacing radioisotopes. The low energies of eBT devices require minimal shielding, potentially improving patient monitoring. The beam flatness is excellent yielding a

Table I A comparison of several physical characteristics of the currently available eBT devices

\begin{tabular}{|c|c|c|c|c|c|c|}
\hline Device & $\begin{array}{l}\text { Maximum } \\
\text { energy }\end{array}$ & Half-value (mm Al) & Dose rate & $\begin{array}{l}\text { Beam } \\
\text { current }\end{array}$ & $\begin{array}{l}\text { Source-surface } \\
\text { distance }\end{array}$ & $\begin{array}{l}\text { Source } \\
\text { diameter }\end{array}$ \\
\hline Xoft $^{\circledR}$ Axxent ${ }^{\circledR}$ & $50 \mathrm{kV}$ & $\begin{array}{l}0.5 \text { (bare source) } \\
\text { I.6 (endocavitary applicator) }\end{array}$ & $\begin{array}{l}0.6 \mathrm{~Gy} / \mathrm{min} \text { at } \\
3 \mathrm{~cm} \text { depth }\end{array}$ & $300 \mu \mathrm{A}$ & $25 \mathrm{~mm}$ & $\begin{array}{l}2.25 \mathrm{~mm} \text { point } \\
\text { source }\end{array}$ \\
\hline Zeiss $^{\circledR}$ INTRABEAM ${ }^{\circledR}$ & $50 \mathrm{kV}$ & $\begin{array}{l}0.1 \text { (bare source) } \\
0.8-1.3 \text { (spherical applicators) }\end{array}$ & $\begin{array}{l}2 \mathrm{~Gy} / \mathrm{min} \text { at } \\
\mathrm{I} \mathrm{cm} \text { depth }\end{array}$ & $5-40 \mu \mathrm{A}$ & $9.6-21.6 \mathrm{~mm}$ & $\begin{array}{l}3.2 \mathrm{~mm} \text { point } \\
\text { source }\end{array}$ \\
\hline Elekta $^{\circledR}$ Esteya $^{\circledR}$ & $69.5 \mathrm{kV}$ & I.83 (surface applicator) & $\begin{array}{l}2.7 \mathrm{~Gy} / \mathrm{min} \text { at } \\
3 \mathrm{~mm} \text { depth }\end{array}$ & $0.5-1.6 \mathrm{~mA}$ & $60 \mathrm{~mm}$ & $\begin{array}{l}\text { Collimated window } \\
\text { type source }\end{array}$ \\
\hline
\end{tabular}

Abbreviations: eBT, electronic brachytherapy; min, minutes. 
smaller penumbra and less total body dose. ${ }^{22}$ Approximately 2,200 radiation therapy departments are treating patients in the United States, but only $\sim 45 \%$ have HDR afterloaders or offer brachytherapy as a treatment option. ${ }^{42}$ eBT devices provide an option to the remaining centers.

Medicare claims for eBT codes have increased drastically over the past few years. In 2013, 24,325 claims for the daily CPT treatment code $0182 \mathrm{~T}$ were submitted, up from only 1,214 claims for the same code submitted in 2011 . The majority of these claims were submitted for the treatment of skin cancer. ${ }^{43}$ While eBT is also used in treating gynecological and other cancers, with intraoperative breast cancer treatment in particular seeing a large increase in use during this time period, these hospital-based procedures are almost always single-fraction treatments. Skin surface treatment with eBT is usually delivered in 6-8 fractions, and eBT skin surface treatments are delivered in both hospital-based and free-standing facilities, including dermatology offices.

eBT seems to be growing more quickly than the new SRT options because eBT reimbursement provides a more feasible economic model. ${ }^{44}$ Despite the requirement that a radiation oncologist must be present with eBT and not with SRT, the fact that eBT treatment results in reimbursement several times that of SRT makes it more viable. Some question the significance of the technical differences between the two types of devices. All of these devices provide effective dose over few to several millimeters, depending on the energy of the source and how deep the dose is specified. The dose rate is usually higher for the eBT devices. The SSD of the three eBT devices range from $16.9 \mathrm{~mm}$ to $60 \mathrm{~mm}$ compared to typical ${ }^{192}$ Ir HDR brachytherapy SSD of 5-15 mm. Traditional SRT machines have SSD as low as $10 \mathrm{~cm}$, but often $50-70 \mathrm{~cm}$. Does this difference justify classification of the eBT devices as "brachytherapy," which means "close therapy?" Perhaps it does if the advantages of eBT allow hypofractionation, as is typically used in isotopic HDR surface brachytherapy, more easily than conventional SRT. While some practitioners deliver large doses per fraction and hypofractionate with SRT, this practice is best used only when late cosmetic toxicity is not important. Typically, traditional SRT, orthovoltage therapy, and electrons are delivered $>3-7$ weeks of daily treatment. ${ }^{27}$ Abbatucci et al described a hypofractionated regimen with SRT in which overall cosmesis was rated in $52 \%$ of patients as "fair or bad", and $>1 / 2$ had visible scarring. ${ }^{36}$ The data from isotopic surface HDR brachytherapy thus far have not shown significant late effects, with many patients followed closely $>5$ years from treatment. ${ }^{13,14}$ The eBT clinical data are too premature to definitively answer this question, but we would expect, with the dosimetric similarities between eBT and isotopic surface HDR brachytherapy, that late effects would be quite similar as well.

While there were reports of increased sales of eBT devices in 2013 and 2014, as well as the introduction of the new dedicated skin surface device Esteya, it is unclear that the growth will continue. While Medicare coverage of eBT was established in some regions with favorable reimbursement rates in 2013 and 2014, Noridian - which is the Medicare Administrative Contractor for 13 Western States including California and Nevada - notified providers in a policy update that most of the codes associated with recent submissions for HDR treatment of skin cancer, including CPT codes (0182T), codes (77261-77370), and codes (77427-77499), were inappropriate and would not be covered as of June 8, 2015. These codes include radiation planning, dosimetry, simulations, and physician-management services. ${ }^{45}$ Providers were instructed to report CPT code (17999). It should be noted that these changes affected both eBT and radionuclide-based HDR. At least one of the eBT device manufacturers has notified shareholders that they have contacted Noridian as well as the Centers for Medicare and Medicaid Services (CMS) to seek clarification of the Medicare Coverage Articles posted to Noridian's website. ${ }^{46}$

\section{Conclusion}

The skin surface is ideally situated for superficial radiotherapy techniques, and eBT appears to be a quick and convenient method to replicate, and possibly improve upon, other radiotherapy techniques for small, superficial lesions. The justification for $\mathrm{EBT}$ is based on the clinical and technical data obtained from radionuclide skin surface brachytherapy and the small skin surface applicators developed over the past 25 years. These devices provide effective dose over a few to several millimeters, depending on the energy of the source and how deep the dose is specified. The data for eBT are very limited, but preliminary reports show excellent responses and minimal toxicity. The implementation of these devices has been rapidly increasing over the past few years, but it is not clear that current reimbursement rates will be maintained to support this growth.

\section{Disclosure}

Dr Kasper is a consultant for Elekta AB-Nucletron, Stockholm, Sweden, for Brachytherapy. The other author reports no conflicts of interest in this work.

\section{References}

1. Cancer.org [homepage on the Internet]. American Cancer Society. Cancer, Facts and Figures. American Cancer Society Inc.; 2015. Available from: http://www.cancer.org/acs/groups/content/@research/documents/webcontent/acspc-042151.pdf. Accessed May 29, 2015. 
2. Rogers HW, Weinstock MA, Harris AR, et al. Incidence estimate of nonmelanoma skin cancer in the United States, 2006. Arch Dermatol. 2010;146(3):283-287.

3. AJCC. American Joint Committee on Cancer Staging Manual. 7th ed. New York: Springer; 2010.

4. Donaldson MR, Coldiron BM. No end in sight: the skin cancer epidemic continues. Semin Cutan Med Surg. 2011;30(1):3-5.

5. Mendenhall WM, Million RR, Mancuso AA, Cassissi NJ, Flowers FP. Carcinoma of the skin. In: Million RR, Cassissi NJ, editors. Management of Head and Neck Cancer: A Multidisciplinary Approach. Philadelphia: Lippincott Williams \& Wilkins; 1994:643-691.

6. Amdur RJ, Kalbaugh KJ, Ewald LM, et al. Radiation therapy for skin cancer near the eye: kilovoltage x-rays versus electrons. Int J Radiat Oncol Biol Phys. 1992;23(4):769-779.

7. Lovett RD, Perez CA, Shapiro SJ, Garcia DM. External irradiation of epithelial skin cancer. Int J Radiat Oncol Biol Phys. 1990;19(2): 235-242.

8. Sabbas AM, Kulidzhanov FG, Presser J, Hayes MK, Nori D. HDR brachytherapy with surface applicators: technical considerations and dosimetry. Technol Cancer Res Treat. 2004;3(3):259-267.

9. Ghadjar P, Bojaxhiu B, Simcock M, et al. High dose-rate versus low dose-rate brachytherapy for lip cancer. Int J Radiat Oncol Biol Phys. 2012;83(4):1205-1212.

10. Orton CG. High-dose-rate brachytherapy may be radiobiologically superior to low-dose-rate due to slow repair of late-responding normal tissue cells. Int J Radiat Oncol Biol Phys. 2001;49(1):183-189.

11. Guix B, Finestres F, Tello J, et al. Treatment of skin carcinomas of the face by high-dose-rate brachytherapy and custom-made surface molds. Int J Radiat Oncol Biol Phys. 2000;41(1):95-102.

12. Kohler-Brock A, Prager W, Pohlmann S, Kunze S. The indications for and the results of HDR afterloading therapy in the diseases of the skin and mucosa with standardized surface applicators (the Leipzig applicator). Strahlenther Onkol. 1999;175(4):170-174.

13. Gauden R, Pracy M, Avery AM, Hodgetts I, Gauden S. HDR brachytherapy for superficial non-melanoma skin cancers. J Med Imaging Radiat Oncol. 2013;57(2):212-217.

14. Tormo A, Celada F, Rodriguez S, et al. Non-melanoma skin cancer treated with HDR Valencia applicator: clinical outcomes. J Contemp Brachytherapy. 2014;6(2):167-172.

15. XoftInc.com [homepage on the Internet]. Axxess with Axxent: Innovative Technology for the Practice of Radiation Oncology. California: Xoft, inc.; 2008. Available from: http://www.xoftinc.com/treatingebx.html. Accessed June 11, 2015.

16. Rong Y, Welsh JS. Surface applicator calibration and commissioning of an electronic Brachytherapy system for nonmelanoma skin cancer treatment. Med Phys. 2010;37(10):5509-5517.

17. Eaton DJ. Electronic brachytherapy - current status and future directions. Br J Radiol. 2015;88(1049):20150002.

18. Khan FM, Gibbons JP. Khan's the Physics of Radiation Therapy. 4th ed. Philadelphia: Lippincott Williams \& Wilkins; 2010.

19. Zeiss.com [homepage on the Internet]. INTRABEAM: Precision and Ease of Use. Jena, Germany: Carl Zeiss Meditec AG, 2014. Available from: http://www.zeiss.com/meditec/en_us/products-solutions/ intraoperative-radiotherapy/intrabeam-for-breast-cancer/intrabeam html. Accessed June 11, 2015.

20. Eaton DJ. Quality assurance and independent dosimetry for an intraoperative x-ray device. Med Phys. 2012;39(11):6908-6920.

21. Esteya.com [homepage on the Internet]. Esteya Electronic Brachytherapy for Treating Skin Cancer. Sweden: Elekta AB, 2015. Available from http://www.esteya.com. Accessed June 11, 2015.

22. Pons-Llanas O, Ballester-Sánchez R, Celada-Álvarez FJ, et al. Clinical implementation of a new electronic brachytherapy system for skin brachytherapy. J of Contemp Brachytherapy. 2015;6(4):417-423.

23. Garcia-Martinez T, Chan JP, Perez-Calatayud J, Ballester F. Dosimetric characteristics of a new unit for electronic skin Brachytherapy. J Contemp Brachytherapy. 2014;6(1):45-53.

24. Rong Y, Zuo L, Shang L, Bazan JG. Radiotherapy treatment for nonmelanoma skin cancer. Expert Rev Anticancer Ther. 2015;8:1-12.
25. Bhatnagar A. Nonmelanoma skin cancer treated with electronic brachytherapy: results at 1 year. Brachytherapy. 2013;12(2):134-140.

26. Ballester-Sánchez R, Pons-Llanas O, Candela-Juan C, et al. Efficacy and safety of electronic brachytherapy for superficial and nodular basal cell carcinoma. J Contemp Brachytherapy. 2015;7:3.

27. Mendenhall WM,Amdur RJ, Hinerman RW, CognettaAB, Mendenhall NP. Radiotherapy for cutaneous squamous and basal cell carcinomas of the head and neck. Laryngoscope. 2009;119(10):1994-1999.

28. Petrovich Z, Parker RG, Luxton G, Kuisk H, Jepson J. Carcinoma of the lip and selected sites of head and neck skin. A clinical study of 896 patients. Radiother Oncol. 1987;8(1):11-17.

29. Silva JJ, Tsang RW, Panzarella T, Levin W, Wells W. Results of radiotherapy for epithelial skin cancer of the pinna: the Princess Margaret Hospital Experience, 1982-1993. Int J Radiat Oncol Biol Phys. 2000;47(2):451-459.

30. Culleton S, Breen D, Assaad D, et al. 5-year review of a unique multidisciplinary nonmelanoma skin cancer clinic. J Cutan Med Surg. 2011;15(4):220-226.

31. Finizio L, Vidali C, Calacione R, Beorchia A, Trevisan G. What is the current role of radiation therapy in the treatment of skin carcinomas? Tumori. 2002;88(1):48-52.

32. Avril MF, Auperin A, Margulis A, et al. Basal cell carcinoma of the face: surgery or radiotherapy? Results of a randomized study. $\mathrm{Br} J$ Cancer. 1997;76(1):100-106.

33. Hall VL, Leppard BJ, McGill J, Kesseler ME, White JE, Goodwin P. Treatment of basal-cell carcinoma: comparison of radiotherapy and cryotherapy. Clin Radiol. 1986;37(1):33-34.

34. Alam M, Nanda S, Mittal BB, Kim NA, Yoo S. The use of brachytherapy in the treatment of nonmelanoma skin cancer: a review. $J$ Am Acad Dermatol. 2011;65(2):377-388.

35. Kasper ME. Surface brachytherapy for squamous and basal cell carcinomas of the skin. J Contemp Brachytherapy. 2014;6(Suppl 1): OA-G201.

36. Abbatucci JS, Boulier N, Laforge T, Lozier JC. Radiation therapy of skin carcinomas: results of a hypofractionated irradiation schedule in 675 cases followed for more than 2 years. Radiother Oncol. 1989;14(2):113-119.

37. Kasper ME, Richter S, Waren N, Benda R, Shang C, Ouhib Z. Complete response of endemic Kaposi sarcoma lesions with high-dose-rate brachytherapy: treatment method, results, and toxicity using skin surface applicators. Brachytherapy. 2013;12(5):495-499.

38. Levine N. Should Dermatologists Offer EBT? Does the World Need this Technology? Dermatology Times [serial on the Internet]. 2015. Available from: http://dermatologytimes.modernmedicine.com/dermatology-times/ news/electronic-surface-brachytherapy. Accessed April 20, 2015.

39. American American Academy of Dermatology (US). Position Statement on Superficial Radiation Therapy and Electronic Surface Brachytherapy of Cutaneous Basal Cell (BCC) and Squamous Cell Carcinomas (SCC). Schaumburg: American Academy of Dermatology and AAD Association; 2013

40. Bhatnagar A, Loper A. The initial experience of electronic brachytherapy for the treatment of non-melanoma skin cancer. Radiat Oncol. 2010;5:87.

41. Rowe DE, Carroll RJ, Day CL. The long -term recurrence rates in previously untreated (primary) basal cell carcinoma: implications for patient follow-up. J Dermatol Surg Oncol. 1989;15(3):315-327.

42. IMV. IMV 2014 Radiation Therapy Market Report. Des Plaines, IL: IMV Medical Information Division; 2014.

43. Linos E, VanBeek M, Resneck J. A sudden and concerning increase in the use of electronic brachytherapy for skin cancer. JAMA Dermatol. 2015;151(7):699-700.

44. Madorsky S. Electronic Brachytherapy for Skin Cancer - A Viable Economic Model? Skin Cancer Connection Blog. Available from: http:// www.ocskincancer.com/blogs/2013/10/30/electronic-brachytherapyfor-skin-cancer-a-viable-economic-model/. Accessed May 20, 2015.

45. Noridian Healthcare Solutions. Coding for High Dose Rate Brachytherapy for Non-Melanoma Skin Cancers. Policy Update, April 20, 2015.

46. iCad Communication. iCad, inc. Announces Information Related to Reimbursement Levels. Available from: http://www.icadmed. com/2015may06.html. Accessed May 20, 2015. 
Medical Devices: Evidence and Research

Dovepress

\section{Publish your work in this journal}

Medical Devices: Evidence and Research is an international, peerreviewed, open access journal that focuses on the evidence, technology, research, and expert opinion supporting the use and application of medical devices in the diagnosis, treatment and management of clinical conditions and physiological processes. The identification of novel

devices and optimal use of existing devices which will lead to improved clinical outcomes and more effective patient management and safety is a key feature. The manuscript management system is completely online and includes a quick and fair peer-review system. Visit http://www. dovepress.com/testimonials.php to read real quotes from authors.

Submit your manuscript here: http://www.dovepress.com/medical-devices-evidence-and-research-journal 